STOMACH

\title{
Long term outcome of patients with gastric marginal zone B cell lymphoma of mucosa associated lymphoid tissue (MALT) following exclusive Helicobacter pylori eradication therapy: experience from a large prospective series
}

\author{
W Fischbach, M-E Goebeler-Kolve, B Dragosics, A Greiner, M Stolte
}

Gut 2004;53:34-37

Background: Helicobacter pylori plays a decisive role in the pathogenesis of gastric marginal zone B cell lymphoma of mucosa associated lymphoid tissue (MALT), and eradication therapy has become a widely accepted initial treatment of stage I disease.

Objective: To determine the long term outcome of patients undergoing exclusive $H$ pylori eradication therapy.

Design: A prospective series of patients with newly diagnosed marginal zone B cell lymphoma of MALT. Setting: Multicentre study in Germany and Austria.

Patients: Ninety five patients; 90 of these (five lost to follow up) with a mean age of 54.3 (27-85) years were followed up for at least 12 months.

See end of article for authors' affiliations

Correspondence to:

Professor W Fischbach,

Medizinische Klinik II,

Klinikum Aschaffenburg,

Am Hasenkopf, D-63739

Aschaffenburg, Germany;

wolfgang.fischbach@

klinikum-aschaffenburg.de

Accepted for publication 5 August 2003
Intervention: Complete staging work up revealing stage I disease and $H$ pylori infection. Patients received triple therapy (OMC: omeprazole $20 \mathrm{mg}$ twice daily, metronidazole $400 \mathrm{mg}$ twice daily, and clarithromycin $250 \mathrm{mg}$ twice daily; or OAC: omeprazole $20 \mathrm{mg}$ twice daily, amoxycillin $1000 \mathrm{mg}$ twice daily, and clarithromycin 500 twice daily) for one week.

Results: Median follow up was 44.6 (12-89) months. H pylori was successfully eradicated in 88 patients (98\%); in two patients eradication therapy failed. Long term outcome was characterised by complete regression of lymphoma in 56 patients (62\%), minimal residual disease in 17 patients (18\%), partial remission in 11 patients $(12 \%)$, no change in four patients $(4 \%)$, and progressive disease in two patients (2\%). Four patients with complete remission relapsed after 6, 8, 8, and 15 months, one revealing reinfection by $H$ pylori. Regression rate was higher in stage 11 disease compared with stage 12 , as diagnosed by endoscopic ultrasound.

Conclusion: The majority of patients with low grade gastric MALT lymphoma treated by exclusive $H$ pylori eradication have a favourable long term outcome, offering a real chance of cure.
$\mathrm{T}$ here is strong evidence from epidemiological, histomorphological, and experimental data that infection of the gastric mucosa by Helicobacter pylori plays a decisive role in the development and progression of marginal zone B cell lymphoma of the mucosa associated lymphoid tissue (MALT) type. ${ }^{1-10}$ This convincing evidence of a pathogenetic link led to a new approach towards treatment. Nowadays, eradication of $H$ pylori is considered the well accepted initial therapy in cases of localised (stage I) low grade gastric MALT lymphoma. ${ }^{11}$ However, data on the long term outcome of patients undergoing exclusive eradication therapy are rare, and the curative potential of this strategy is still under debate. We report a large prospective series of 90 patients with a follow up of at least 12 months.

\section{METHODS}

From March 1993 onwards, 95 patients were diagnosed as having gastric marginal zone B cell lymphoma of the MALT type by centralised histological review. The diagnosis was based on morphological and immunophenotypic analysis of paraffin embedded sections and, when available, fresh frozen material. Histological work up followed the criteria described by Isaacson and Norton ${ }^{12}$ and the REAL/WHO classification. $^{13}{ }^{14}$ The endoscopic biopsy protocol comprised 8-12 samples of visible lesions and two separate biopsies from macroscopically normal mucosa of the antrum and corpus.
Complete staging work up, including abdominal and cervical ultrasound, computed tomography scan of the chest and abdomen, bone marrow puncture, small bowel radiography, ileocolonoscopy, and endoscopic ultrasound (EUS) revealed stage I according to the Ann Arbor staging system with its modifications by Musshoff ${ }^{15}$ and Radaszkiewicz and colleagues. ${ }^{16}$ Due to lack of availability, EUS could not be performed in 10 cases.

$H$ pylori infection was diagnosed if the urease rapid test, histology, or the ${ }^{13} \mathrm{C}$ urea breath test were positive. Triple therapy using omeprazole $(2 \times 20 \mathrm{mg} /$ day $)$, clarithromycin $(2 \times 250 \mathrm{mg} /$ day and $2 \times 500 \mathrm{mg} /$ day, respectively $)$, and metronidazole $(2 \times 400 \mathrm{mg} /$ day $) \quad(\mathrm{OMC})$ or amoxycillin $(2 \times 1000 \mathrm{mg} / \mathrm{day})(\mathrm{OAC})$ was given for seven days. Follow up examinations including endoscopy and ultrasound were carried out at three monthly intervals during the first two years, and every six months thereafter.

Ninety of the patients (33 female, 57 male; mean age 54.3 years (range 27-85)) were evaluated for their state of remission at 12 months after eradication therapy; five patients were lost to follow up. Complete remission was

Abbreviations: MALT, mucosa associated lymphoid tissue; OMC omeprazole, metronidazole, and clarithromycin; OAC, omeprazole, amoxycillin, and clarithromycin; EUS, endoscopic ultrasound 
defined as total disappearance of lymphoma and absence of histopathological evidence of lymphoma on endoscopic biopsy. Partial remission was assumed in cases of tumour reduction of at least $50 \%$. Patients revealing normalisation of macroscopic findings but with persistent residual lymphoma infiltrates on histological examination were classified as minimal residual disease.

In cases of non-response to $H$ pylori eradication, defined as clinically or histologically progressive disease at any control, partial remission, or no change 12 months after successful eradication of $\mathrm{H}$ pylori, patients were referred for surgery or radiotherapy. In those with minimal residual disease, any oncological treatment was postponed on condition of very thorough endoscopic-bioptic controls.

To estimate the effect of $H$ pylori eradication therapy on lymphoma status, intention to treat analysis was applied.

The study was approved by the ethics committees of the Universities of Würzburg and Vienna. All patients gave written informed consent.

\section{RESULTS}

Median follow up was 44.6 months (range 12-89). H pylori eradication was successful in 88 patients (98\%); in two patients eradication therapy failed. Long term outcome was characterised by complete regression of lymphoma in 56 patients $(62 \%)$, minimal residual disease in 17 patients ( $18 \%)$, partial remission in 11 patients $(12 \%)$, no change in four patients $(4 \%)$, and progressive disease in two patients $(2 \%)$. Figure 1 summarises the long term outcome of all 90 patients.

Four patients relapsed, three with a low grade lymphoma after 8, 8, and 15 months, respectively, and one with a high grade lymphoma after six months. At the time of relapse, only one patient presented with reinfection by $H$ pylori. Additional antibiotic treatment was successful with respect to both bacterial eradication and regression of lymphoma in this patient. He remains free of relapse to date. Two further patients with no change in lymphoma infiltration after eradication therapy were diagnosed as having high grade lymphoma components by endoscopic-bioptic restaging. Two patients died, one from postoperative sepsis after nonresponse to $H$ pylori eradication therapy and one from causes unrelated to lymphoma or its treatment. Patients with minimal residual disease one year after eradication therapy did not reveal any signs of lymphoma progression, spread of disease, or high grade transformation. In two, late complete remission became evident 15 and 19 months after eradication of $H$ pylori.

Complete regression of the lymphoma was observed in 50 of 80 patients $(62.5 \%)$ who were classified as stage I disease by EUS (table 1). In 23 of 50 cases, the endoscopist was unable to differentiate stages Il and I2 by describing the exact depth of tumour infiltration. The rate of complete regression increased from stage I2 $(4 / 9 ; 44 \%)$ to stage Il (23/ $42 ; 55 \%)$.

\section{DISCUSSION}

In the late 1980s, acquisition of intramucosal lymph follicles and accumulation of immunoglobulin A producing plasma cells were found to result from $H$ pylori infection of the gastric mucosa. ${ }^{12}{ }^{17}$ This acquired lymphatic tissue showed morphological characteristics of MALT and regressed after successful eradication of the bacterium. ${ }^{18}$ In 1991, Wotherspoon and colleagues $^{3}$ for the first time demonstrated that patients with primary gastric MALT lymphoma are regularly infected by $H$ pylori. Since then, this finding has been confirmed by other investigators. ${ }^{4}{ }^{18}{ }^{19}$ In addition to histomorphological studies, recent epidemiological, ${ }^{56}$ molecular biological, ${ }^{8-10}$ and experimental ${ }^{7}$ data clearly indicate that $H$ pylori plays a decisive role in the development and progression of gastric MALT lymphoma. This convincing evidence inevitably involved a therapeutic effort. In 1993, Wotherspoon and colleagues ${ }^{20}$ reported complete regression of low grade lymphoma following successful $H$ pylori eradication in five of six cases. Prospective trials have confirmed this observation ${ }^{21-26}$ and reported rates of complete regression of lymphoma varying between $56 \%$ and $100 \%$.

Undoubtedly, eradication of $H$ pylori represents a fascinating therapeutic option because of both its simplicity and efficacy. However, data on long term outcome are currently rare. To our knowledge, our series is one of the largest prospective studies on $H$ pylori eradication therapy in gastric MALT lymphoma, and with a median follow up of more than four years comprises one of the longest observation periods. In 1999, Isaacson described a six year follow up of the first six patients who were successfully treated by $H$ pylori eradication. ${ }^{27}$ Although transient histological or molecular relapse has been observed in some patients, prolonged disease free remission was documented in all patients with or without molecular evidence of a monoclonal B cell population. The

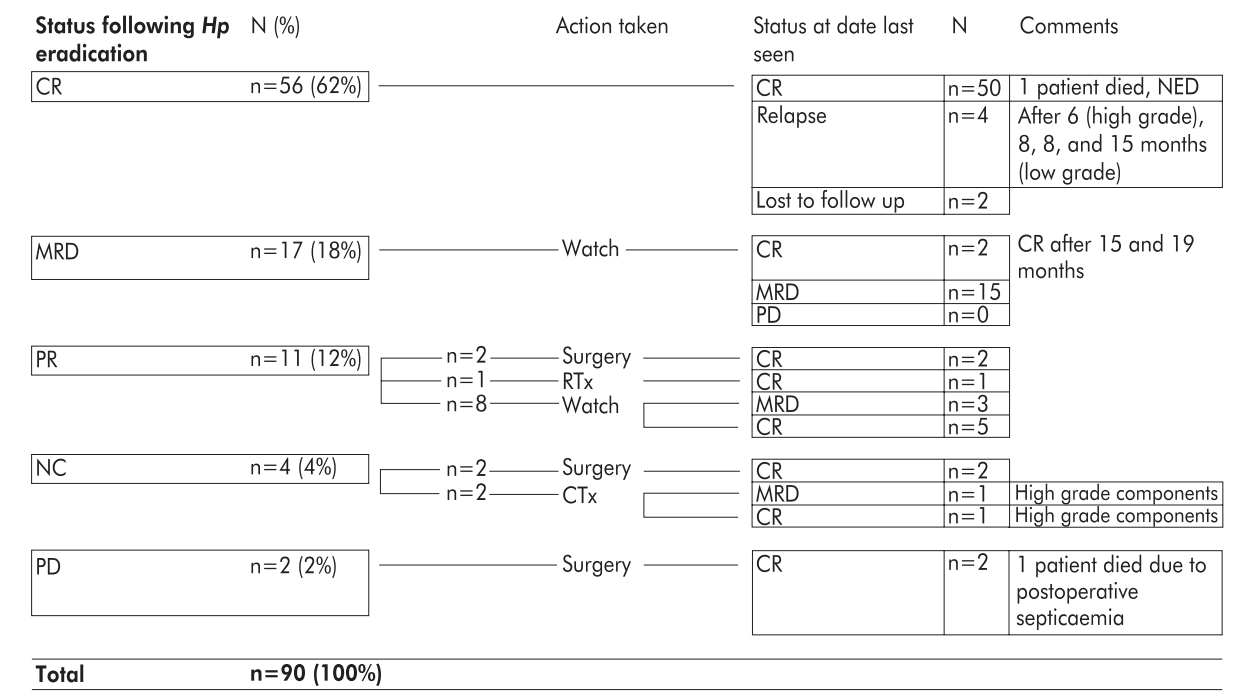

Figure 1 Status of patients after Helicobacter pylori eradication therapy and during further follow up. CR, complete remission; MRD, minimal residual disease; PR, partial remission; NC, no change; PD, progressive disease; RTx, radiotherapy; CTx, chemotherapy; NED, no evidence of disease. 
Table 1 Outcome of patients after Helicobacter pylori eradication therapy in relation to endosonographic findings at the time of diagnosis

\begin{tabular}{lrrrlll}
\hline EUS & CR & MRD & PR & NC & PD & Total \\
\hline 11 & 23 & 10 & 5 & 3 & 1 & 42 \\
12 & 4 & 0 & 4 & 0 & 1 & 9 \\
I $^{*}$ & 23 & 3 & 2 & 1 & 0 & 29 \\
No EUS & 6 & 4 & 0 & 0 & 0 & 10 \\
Total & 56 & 17 & 11 & 4 & 2 & 90 \\
\hline
\end{tabular}

EUS, endoscopic ultrasound; CR, complete remission; MRD, minimal residual disease; PR, partial remission; NC, no change; PD, progressive disease.

*In some participating centres, differentiation between stages 11 and 12 by EUS was not possible for reasons of technical quality or endoscopist's experience; therefore, stages II and I2 are not discriminated.

overall complete lymphoma regression rate in our study of $62.5 \%$ does not differ considerably from studies with a shorter follow up..$^{21-26}$

Assessment of the depth of lymphoma infiltration by endoscopy and EUS has thus far been shown to have predictive value. ${ }^{23} 26^{28-30}$ However, the findings reported in these studies vary widely. While Ruskoné-Fourmestraux et al describe complete remission rates as high as $79 \%$ in lymphomas infiltrating the mucosa only, ${ }^{28}$ Steinbach et al achieved complete remission in stage 1 patients of no more than $56 \%{ }^{26}$ What are the possible explanations for these discrepancies? It has to be kept in mind that the diagnostic accuracy of EUS in the local staging of gastric lymphoma is limited. We found that EUS correctly identified only 53\% of patients compared with the gold standard of pathohistological stage of the resected specimen. ${ }^{31}$ This was a multicentre study, thus probably reflecting the situation in a more realistic way than results from highly specialised gastroenterology units. ${ }^{28}{ }^{30}$ Finally, experience with EUS was limited at the time this study started. We strongly believe that with increasing experience of endoscopists and technical improvements such as the use of small ultrasound probes (mini-echoendoscopes) and ultrasound guided biopsy facilities, EUS as a predictive factor of lymphoma remission will become substantially more accurate. Considering the diagnostic uncertainty on the one hand and possible regression of lymphoma even in locally more advanced stages, we would not at present exclude patients with infiltration of the submucosa or muscularis propria from eradication therapy. However, they may need a more intensive follow up.

Relapse was found in four patients, one of whom had a high grade lymphoma. In view of the comparatively short time period (six months) until relapse recurred in the latter patient, it remains a matter of speculation whether this was in fact recurrence or previously undiagnosed high malignant foci of the initial lymphoma. According to our experience in 266 patients with primary gastric B cell lymphoma, approximately $18 \%$ reveal synchronous low grade and high grade components. ${ }^{24}$ The fact that high grade lymphoma was found in only three patients (fig 1) allows two conclusions to be drawn. Firstly, the risk of high malignant transformation in patients treated by exclusive $H$ pylori eradication appears to be low. Secondly, a subtle endoscopic-bioptic technique (gastric mapping), as performed here, minimises sampling errors.

With respect to both the rate of relapse and $H$ pylori reinfection, our data are very similar to those reported by Neubauer and colleagues. ${ }^{25}$ In their prospective series of 50 patients, they observed four cases of local recurrence, only one being accompanied by $H$ pylori reinfection. Another patient developed a high grade nasal lymphoma. This study offers another highly interesting aspect. In 22 of 31 patients $(71 \%)$ with continuous complete remission, monoclonal $\mathrm{B}$ cells persisted. The biological significance of these cells is not clear at present.
Eighteen per cent of patients studied were characterised by normalised endoscopic and endosonographic findings but persistent lymphoma infiltrates (minimal residual disease). Despite well established criteria to refer such patients to surgery or radiotherapy, we decided on a watch and wait strategy after extensive and repeated information from the patients. Our findings that they did well during further follow up, focus on a possibly favourable natural course of minimal residuals of low grade gastric MALT type lymphoma after successful eradication of $H$ pylori. Molecular analyses were beyond the scope of this multicentre study. With respect to translocation $t(11 ; 18)$, discordant results have been published recently. ${ }^{32-35}$ There is some evidence that $t(11 ; 18)$ positive lymphoma are characterised by a more advanced tumour stage and failure to respond to $H$ pylori eradication therapy. ${ }^{32}{ }^{33}$ On the other hand, $\mathrm{t}(11 ; 18)$ negative lymphoma reveal more clonal aberrations and are prone to progress more frequently to high grade lymphoma. ${ }^{34}$ In a small series, we have shown that minimal residuals of low grade gastric MALT type lymphoma patients being $t(11 ; 18)$ positive may have a favourable course of disease. ${ }^{35}$ Hence a watch and wait strategy may become an option in such a situation.

In summary, $H$ pylori eradication is an effective treatment modality in gastric marginal zone B cell lymphoma of MALT. The majority of patients treated exclusively in this way have a favourable long term outcome, offering a real chance of cure.

\section{ACKNOWLEDGEMENT}

Supported by a grant from the Deutsche Krebshilfe (German Cancer Research Foundation).

\section{Authors' affiliations \\ W Fischbach, Department of Internal Medicine, Klinikum Aschaffenburg, Aschaffenburg, Germany \\ M-E Goebeler-Kolve, Medizinische Poliklinik, University of Würzburg, Würzburg, Germany \\ B Dragosics, Gesundheitszentrum Süd, Vienna, Austria \\ M Stolte, Institute of Pathology, Klinikum Bayreuth, Bayreuth, Germany \\ A Greiner, Institute of Pathology, University of Würzburg, Würzburg, Germany}

Presented and published as an abstract at the Digestive Disease Week, Atlanta, May 2001.

\section{REFERENCES}

1 Stolte $M$, Eidt S. Lymphoid follicles in antral mucosa: Immune response to Campylobacter pylori? J Clin Pathol 1989;42:1269-71.

2 Wyatt Jl, Rathbone BJ. Immune response of the gastric mucosa to Campylobacter pylori. Scand J Gastroenterol 1988;23(suppl 142):135-40

3 Wotherspoon AC, Ortiz-Hildalgo C, Falzon MR, et al. Helicobacter pyloriassociated gastritis and primary B-cell gastric lymphoma. Lancet 1991;338:1175-6.

4 Eck M, Schmaußer W, Haas R, et al. MALT-type lymphoma of the stomach is associated with Helicobacter pylori strains expressing the Cag A protein. Gastroenterology 1997; 112:1482-6. 
5 Doglioni C, Wotherspoon AC, Moschini A, et al. High incidence of primary gastric lymphoma in northeastern Italy. Lancet 1992;339:834-5.

6 Parsonnet J, Hansen S, Rodriguez L, et al. Helicobacter pylori infection and gastric lymphoma. N Engl J Med 1994;330:1267-71.

7 Enno A, O'Rourke J, Lee A, et al. MALToma-like lesions in the stomach resulting from longstanding Helicobacter infection in the mouse. Am J Gastroenterol 1994;89:1357.

8 Greiner A, Marx A, Heesemann J, et al. Idiotype identity in a MALT-type lymphoma and B cells in Helicobacter pylori associated chronic gastritis. Lab Invest, 1994;70:572-8.

9 Hussell T, Isaacson PG, Crabtree JE, et al. The response of cells from lowgrade B-cell gastric lymphomas of mucosa-associated lymphoid tissue to Helicobacter pylori. Lancet 1993;342:571-4.

10 Hussell T, Isaacson PG, Crabtree JE, et al. Helicobacter pylori specific tumour infiltrating $T$ cells provide contact dependent help for the growth of malignant $B$ cells in low-grade gastric lymphoma of mucosa-associated lymphoid tissue. J Pathol 1996;178:122-7.

11 Fischbach W. Primary gastric lymphoma of MALT: Considerations of pathogenesis, diagnosis and therapy. Can J Gastroenterol 2000;14(suppl D): $44 \mathrm{D}-50$

12 Isaacson PG, Norton AJ. Extranodal lymphomas. Edinburgh: Churchill Livingstone, 1994

13 Harris NL, Jaffe ES, Stein $\mathrm{H}$, et al. A revised European-American classification of lymphoid neoplasms. A proposal from the international lymphoma study group. Blood 1994:84:1361-92.

14 Harris NL, Jaffe ES, Diebold J, et al. World Health Organization Classification of Neoplastic Diseases of Hematopoetic and Lymphoid Tissues: Report of the Clinical Advisory Committee Meeting Airlie House, Virginia, November 1997. Hematol J 2000; 1:53-66.

15 Musshoff K. Klinische Stadieneinteilung der nicht-Hodgkin Lymphome. Strahlentherapie 1977;153:218-21.

16 Radaszkiewicz TH, Dragosics B, Bauer P. Gastrointestinal malignant lymphomas of the mucosa-associated lymphoid tissue. Factors relevant to prognosis. Gastroenterology 1992;102:1628-38.

17 Kirchner TH, Melber A, Fischbach W, et al. Immunohistological patterns of the local immune response in Helicobacter pylori gastritis. In: Malfertheiner $\mathrm{P}$, Ditschuneit $\mathrm{H}$, eds. Helicobacter pylori, gastritis and peptic ulcer. Berlin, Heidelberg: Springer, 1990:213-22.

18 Stolte $\mathrm{M}$, Eidt S. Healing gastric MALT-lymphomas by eradicating $\mathrm{H}$. pylori ? Lancet 1993;342:568

19 Eidt S, Stolte M, Fischer R. Helicobacter pylori gastritis and gastric nonhodgkin's lymphoma. J Clin Pathol 1994:47:436-9.

20 Wotherspoon AC, Doglioni C, Diss TC, et al. Regression of primary low-grade B-cell gastric lymphoma of mucosa-associated lymphoid tissue type after eradication of Helicobacter pylori. Lancet 1993;342:575-7.
21 Bayerdörffer E, Neubauer A, Rudolph B, et al. Regression of primary gastric lymphoma of mucosa-associated lymphoid tissue type after cure of Helicobacter pylori infection. Lancet 1995;345:1591-4.

22 Roggero E, Zucca E, Pinotti G, et al. Eradication of Helicobacter pylori infection in primary low-grade gastric lymphoma of mucosa-associated lymphoid tissue. Ann Intern Med 1995; 122:767-9.

23 Nobre-Leitao C, Lage P, Cravo M, et al. Treatment of gastric MALT lymphoma by Helicobacter pylori eradication: A study controlled by endoscopic ultrasound. Am J Gastroenterol 1998;93:732-6.

24 Fischbach W, Dragosics B, Kolve-Goebeler ME, et al. Primary gastric B-cell lymphoma: results of a prospective multicenter study. Gastroenterology 2000;119:1191-202.

25 Neubauer A, Thiede $\mathrm{CH}$, Morgner A, et al. Cure of Helicobacter pylori infection and duration of remission of low-grade gastric mucosa-associated lymphoid tissue lymphoma. J Natl Cancer Inst 1997;89:1350-5.

26 Steinbach G, Ford R, Glober G, et al. Antibiotic treatment of gastric lymphoma of mucosa-associated lymphoid tissue. Ann Intern Med 1999;131:88-95.

27 Isaacson P, Wotherspoon AC, Barbazza R, et al. Long-term follow-up of gastric MALT lymphoma treated by eradication of $\mathrm{H}$. pylori with antibiotics. Gastroenterology 1999; 117:750-1.

28 Ruskoné-Fourmestraux A, Lavergne A, Aegerter PH, et al. Predictive factors for regression of gastric MALT lymphoma after anti-Helicobacter pylori treatment. Gut 2001;48:297-303.

29 Sackmann M, Morgner A, Rudolph R, et al. Regression of MALT lymphoma following eradication of Helicobacter pylori is predicted by endosonographic staging. Gastroenterology 1997;1 13:1087-90.

30 Nakamura S, Matsumoto T, Suekane $\mathrm{H}$, et al. Predictive value of endoscopic ultrasonography for regression of gastric low grade and high grade MALT lymphomas after eradication of Helicobacter pylori. Gut 2001;48:454-60.

31 Fischbach W, Goebeler-Kolve ME, Greiner A. Diagnostic accuracy of endoscopic ultrasound (EUS) in the local staging of primary gastric lymphoma: Results of a prospective study comparing EUS with the pathohistological stage. Gastrointest Endosc 2002;56:696-700.

32 Alpen B, Neubaver A, Dierlamm J, et al. Translocation $t(11 ; 18)$ absent in early gastric marginal zone B-cell lymphoma of MALT type responding to eradication of Helicobacter pylori infection. Blood 2000;95:4014-15.

33 Liu H, Ruskoné-Fourmestraux A, Lavergne-Slove A, et al. Resistance of $t(11 ; 18)$ positive gastric mucosa-associated lymphoid tissue lymphoma to Helicobacter pylori eradication therapy. Lancet 2001;6:39-40.

34 Starostik P, Patzner J, Greiner A, et al. Gastric marginal B-cell lymphomas of MALT-type develop along two distinct pathogenetic pathways. Blood 2002;99:3-9.

35 Fischbach W, Goebeler-Kolve M, Starostik P, et al. Minimal residual low grade gastric MALT-type lymphoma after eradication of Helicobacter pylori. Lancet 2002;360:547-8. 